\title{
ELECTROCHEMICAL COPOLYMERIZATION OF CROSS-LINKABLE POLYTHIOPHENE AND CARBAZOLE
}

\author{
CHUANG GAO*, MEISHAN PEI, QIWEI PAN*
}

Key Laboratory of Chemical Sensing \& Analysis in Universitiesof Siman), School of Chemistry and Chemical Engineering, University of Jinan, Jinan 250022, China. of Shandong (University University of Jinan, Jinan 250022, China

(Received: September 23, 2011 - Accepted: January 13, 2012)

\begin{abstract}
The copolymerization of carbazole $(\mathrm{C})$ and poly3-ethyl-3-(\{[6-(3-thienyl)hexyl]oxy $\}$-methyl)oxetane(PTO) was successfully achieved electrochemically in $\mathrm{CH}_{2} \mathrm{Cl}_{2}$ containing $25 \%$ boron trifluoride diethyl etherate $\mathrm{BFEE}$ (by volume) as supporting electrolyte by direct anodic oxidation of the monomer mixtures on platinum or an optically transparent ITO electrode. As-formed copolymer own the advantages of PTO, such as good electrochemical behaviors, excellent ambient stability. The structure of the copolymer were investigated by UV-vis, fluorescence spectra and thermal analysis, respectively. The fluorescence spectra indicate that PPTOC films are yellow-light emitters. Thermal analysis studies confirmed PPTOC has a good thermal stability.
\end{abstract}

Keywords Polythiophene; Electrochemical polymerization; carbazole; Copolymerization; Boron trifluoride diethyl etherate

\section{INTRODUCTION}

Inherently conducting polymers with $\pi$-conjugated electronic structures have been widely investigated since the late decades [1-3] due to their potential industrial applications based on their high conductivity and organic light-emitting. Conducting polymers are currently the subject of a board research area, especially for the applications in electronic and electrochemical devices such as organic field-effect transistors(OFETs),[4] organic lightemitting diodes(OLEDs),[5] polymer solar cells(PSCs),[6] and sensors. [7] Among these polymers, Poly(thiophenes) and poly(fluorene) have been received considerable attention. Such as poly(thiophenes) have been used in the development of electronic,[8] energy storage batteries,[9] photochromic devices,[10] and nonlinear optical devices.[11] The synthesis of conducting polymer films has been also an increasingly important subject of intensive research.[12-14]

Polythiophenes(PTs) and their derivatives, as a class of conducting polymers, have attracted considerable attention due to their good conductivity and chemical stability in both the neutral and doped states.[15] To improve the optoelectronic properties and to realize the special applications, chemical modifications have been well performed,[16] one of which is the introduction of substituent with functional groups. So we synthesized a novel oxetanefunctionalized cross-linkable conjugated polymer(PTO).[17]

It is well known that copolymerization is one of efficient approaches to modify the properties of conducting polymers, which can produce copolymers with properties being intermediate between individual polymers. By means of the electrochemical copolymerization, some new conducting polymers have been prepared with several obvious advantages, such as variation of electrical conductivity, enhancement of electrochemical activity, and improvement of thermalstability.

In this paper we report on the use of oxetane-functionalized cross-linkable conjugated polythiophene(PTO) and carbazole (C) were copolymerized successfully by direct electrochemical oxidation in $\mathrm{CH}_{2} \mathrm{Cl}_{2}$ containing additional $25 \%$ (by volume) BFEE. The electrochemistry of copolymers(PPTOC) were studied. In addition, the spectroscopic properties, and thermal stability of the copolymer were also investigated in detail.

\section{EXPERIMENTAL}

2.1. Materials

3-(6-Bromohexyl)thiophene (BHT) was synthesized by reaction of 3-bromothiophene (aladdin) with 1,6-dibromohexane (aladdin) in hexane solution using BuLi (aladdin) as reducing agent under the atmosphere of $\mathrm{N}_{2}$ as illustrated in Scheme 1. Boron trifluoride diethyl etherate (BFEE), Sinopharm Chemical Regagent Co., Ltd) was distilled and stored at $-20 \square$ before use.

Preparation of TO

The oxetane-substituted conjugated polymer was prepared by Scheme 1.[17] ${ }^{1} \mathrm{H}$ NMR $\left(\mathrm{CDCl}_{3}\right), \delta(\mathrm{ppm}): 7.25(\mathrm{t}, 1 \mathrm{H}), 6.92(\mathrm{t}, 2 \mathrm{H}), 4.46(\mathrm{~d}, 2 \mathrm{H})$, 4.36(d,2H), $3.53(\mathrm{~s}, 2 \mathrm{H}), 3.47(\mathrm{t}, 2 \mathrm{H}), 2.64(\mathrm{t}, 2 \mathrm{H}), 1.78(\mathrm{~m}, 2 \mathrm{H}), 1.61(\mathrm{~m}, 4 \mathrm{H})$, $1.39(\mathrm{~m}, 4 \mathrm{H}), 0.90(\mathrm{t}, 3 \mathrm{H})$. We use toluene instead of hexane, which yied $72 \%$, better than $63 \%$.

Chemical Ploymerizations

PTO via BFEE to chemical ring opening. $[18]^{\circ} \mathrm{C}, \mathrm{C} 1\left(1.2 \times 10^{-2} \mathrm{~mol}, 2.976 \mathrm{~g}\right)$,
$\mathrm{CH}_{2} \mathrm{Cl}_{2} 9.6 \mathrm{ml}, \mathrm{BF}_{3} \mathrm{O}\left(\mathrm{C}_{2} \mathrm{H}_{5}\right)_{2}\left(3 \times 10^{-3} \mathrm{~mol}, 0.768 \mathrm{ml}\right)$. After $48 \mathrm{~h}$, ethanol end the reaction, then extracted with $\mathrm{CH}_{2} \mathrm{Cl}_{2}$ and washed with water $(3 \times 200 \mathrm{~mL})$. The organic layer was dried over anhydrous $\mathrm{MgSO}_{4}$, filtered, and concentrated.

Electrochemical Polymerizations.

PPTOC electrochemical by BFEE. High quality freestanding polythiophene network films were synthesized successfully in $\mathrm{CH}_{2} \mathrm{Cl}_{2}$ containing additional $25 \%$ (by volume) BFEE by direct anodic oxidation.

2.2. Characterization

All reactions were carried out under a dry nitrogen atmosphere. $\mathrm{CH}_{2} \mathrm{Cl}_{2}$ were distilled over calcium hydride. All solvents were distilled under nitrogen and saturated with nitrogen prior to use. UV-visible spectra were taken by using Perkin Elmer Lambda 900 UV-vis-NIR spectrophotometer. The ${ }^{1} \mathrm{H}-\mathrm{NMR}$ spectrum was recorded on a Bruker AV $400 \mathrm{NMR}$ spectrometer and $\mathrm{CDCl}_{3}$ was used as the solvent. The thermogravimetric analysis(TGA) was performed with a thermal analyzer of Netzsch TG 209. The fluorescence properties were determined with Hitachi F-4500 fluorescence spectrophotometer.

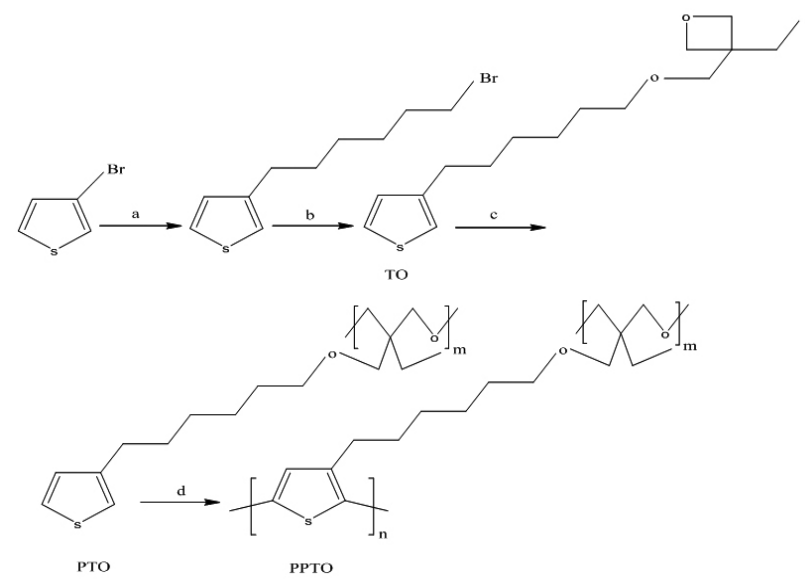

Scheme 1: (a) BuLi, toluene, THF, reflux, 1,6-dibromohexane, THF; (b)3ethyl-3-oxetanemethanol, $\mathrm{NaOH}$, toluene, reflux, 8h; (c) BFEE, $\mathrm{CH}_{2} \mathrm{Cl}_{2}$; (d) BFEE, $\mathrm{CH}_{2} \mathrm{Cl}_{2}$.

\section{RESULTS AND DISCUSSION}

3.1. Electrochemistry copolymerization

The successive cyclic voltammograms (CVs) of mixtures of the two monomers with various feed ratios on a Pt electrode in $\mathrm{BFEE}$ and $\mathrm{CH}_{2} \mathrm{Cl}_{2}$ were shown in Figure 1 and Scheme 2. C could be reduced and oxidized between -0.68 and $0.20 \mathrm{~V}$ (Fig. 1 a). On the other hand, CVs of PTO:C(1:3) showed broad redox waves with reduction and oxidation peaks at -0.72 and $0.30 \mathrm{~V}$ (Fig. 1 b), CVs of PTO:C(1:1) showed broad redox waves with reduction and oxidation peaks at -0.73 and $0.35 \mathrm{~V}$ (Fig. $1 \mathrm{c}$ ), CVs of PTO:C(3:1) showed broad redox waves with reduction and oxidation peaks at -0.68 and $0.29 \mathrm{~V}$ (Fig. 1 d). 


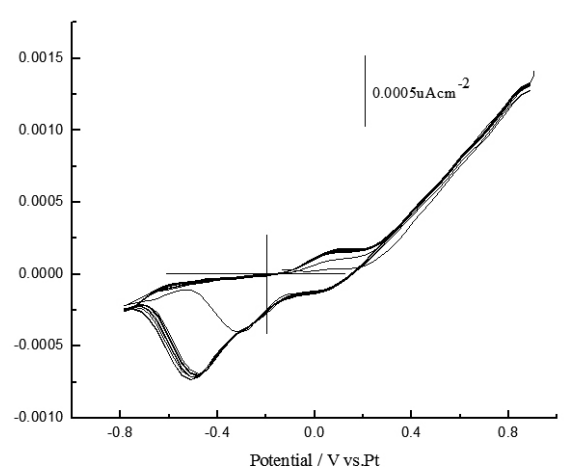

a

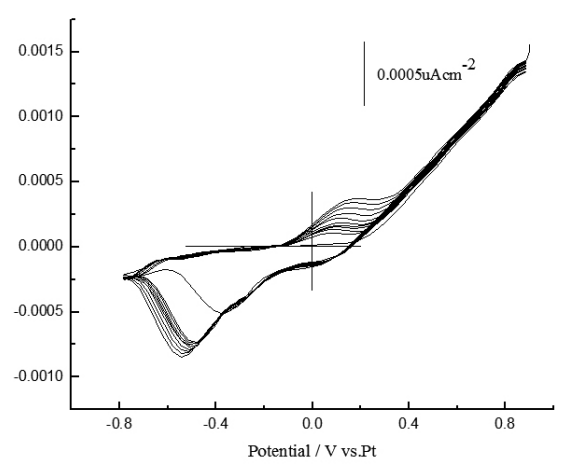

b

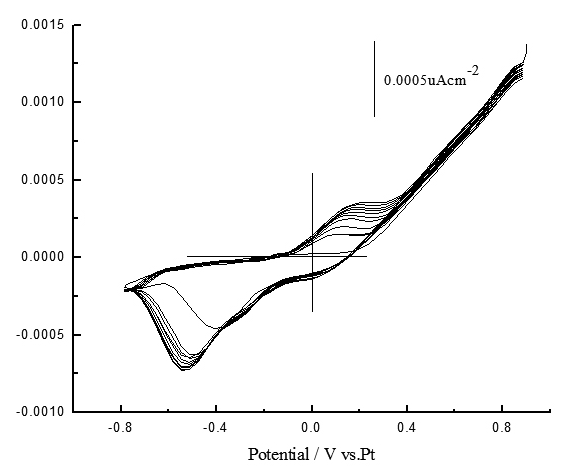

$\mathrm{C}$

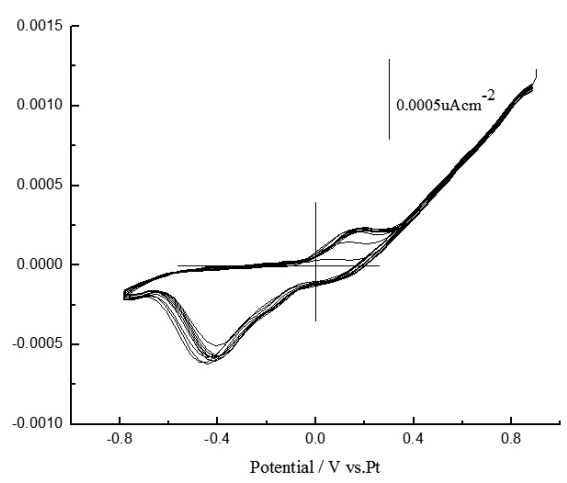

d

Figure 1: Cyclic Voltammograms of C (a), PTO:C(1:3) (b), PTO:C(1:1) (c), PTO:C(3:1) (d), in $\mathrm{CH}_{2} \mathrm{Cl}_{2}$ containing $25 \%$ BFEE (by volume) BFEE. Potential scan rate: $100 \mathrm{mV} \cdot \mathrm{s}^{-1}$.

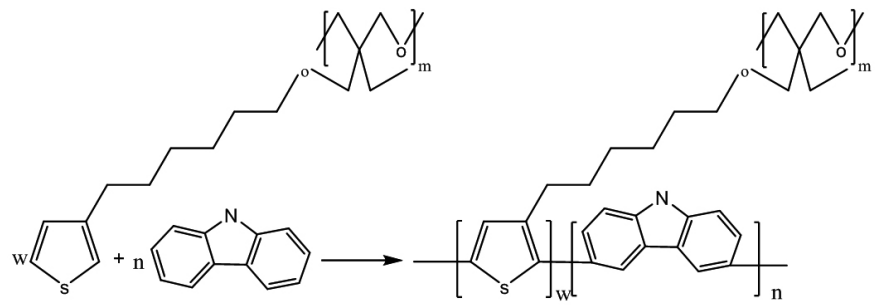

Scheme 2: $\mathrm{BFEE}, \mathrm{CH}_{2} \mathrm{Cl}_{2}$.

It is clearly shown that on the first CV cycle, the current on the reverse scan was higher than that on the forward scan. The formation of this loop was characteristic of nucleation processes and only appeared on the first CV cycle. At the same time, with the potential scans continues, a polymer film was formed on the electrode surface. The increases of the redox wave currents implied that the amount of the polymer on the electrode surface has increasing. The potential shift of this maximum provided information about the increase of the electrical resistance in the polymer film and the over-potential was needed to overcome the resistance. All these phenomena indicated that high-quality PPTOC films were formed on the anode surface.

3.2 UV-vis and Fluorescence Spectra

The UV-visible spectra of $\mathrm{C}$, PTO prepared from $\mathrm{CH}_{2} \mathrm{Cl}_{2}$, PPTOC [PTO:C(3:1)]prepared from $\mathrm{CH}_{2} \mathrm{Cl}_{2}$ containing $25 \% \mathrm{BFEE}$ (by volume) $\mathrm{BFEE}$ are shown in Figure 2. The UV spectrum of the monomer $\mathrm{C}$ shows peaks at $235,291 \mathrm{~nm}$. PTO shows peaks at $236 \mathrm{~nm}$. On the contrary, the spectra of the copolymer have a much broader absorption at $308,373,698 \mathrm{~nm}$. The longer wavelength in the spectra indicated a longer polymer sequence.[19] These spectral results also confirmed a conjugated copolymer formation with a broad molarmass distribution.

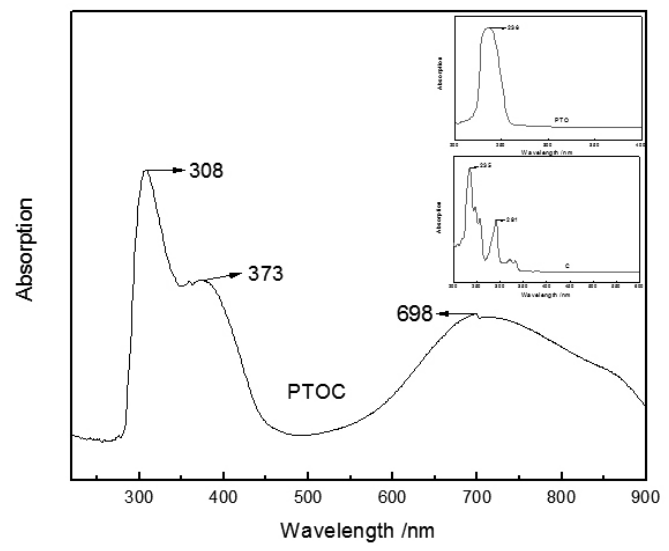

Figure 2: UV-visible spectra of $\mathrm{C}$, PTO in $\mathrm{CH}_{2} \mathrm{Cl}_{2}$, and the PPTOC [PTO:C(3:1)] films coated on an optically transparent ITO electrode.

The emission spectra of the $\mathrm{C}$, PTO, PPTOC [PTO:C(3:1)] as shown in Figure 3. As shown in the figure, an obvious emission peak was found at 314 $\mathrm{nm}$ for PTO and $341,354 \mathrm{~nm}$ for C, while the emission peak of the PPTOC films was found at $392,418,440 \mathrm{~nm}$. The red shift of emission peak indicated that longer conjugation PPTOC was formed.[20] These results imply that PPTOC may be used in yellow light-emitting material.

\subsection{Thermal Analysis}

The polymer films prepared electrochemically by using $\mathrm{CH}_{2} \mathrm{Cl}_{2}$ containing $25 \%$ BFEE(by volume) thermal analysis of PPTOC [PTO:C(3:1)] was shown in Figure 4. The thermal analysis of PPTOC was tested under a nitrogen stream from 300 to $1000 \mathrm{~K}$ with a heating rate of $10 \mathrm{~K} / \mathrm{min}$. The highest temperature $1030 \mathrm{~K}$ is much higher than $680 \mathrm{~K}[17]$. These results imply that chemical ploymerizations and electrochemistry formed network PPTOC. There are two steps in weight loss. The first one is from 300 to $400 \mathrm{~K}$, up to $10 \%$, which can be ascribed to water evaporation or other moisture trapped in the polymer. The second occurred from $400 \mathrm{~K}$ to $580 \mathrm{~K}$ with a weight loss $15 \%$. This was mainly due to the ions doped polymer degradation and the degradation of the polymer 
contained in the oligomers. The main one occurred from $580 \mathrm{~K}$ to $750 \mathrm{~K}$, up to $33 \%$, which was attributed to the degradation radiation of the PPTOC. The main weight loss of PPTOC was found from $750 \mathrm{~K}$ to $1000 \mathrm{~K}$ with a weight loss of 34\%, which results from the degradation of the PPTOC main backbone. All these results indicate that PPTOC has a good thermal stability.

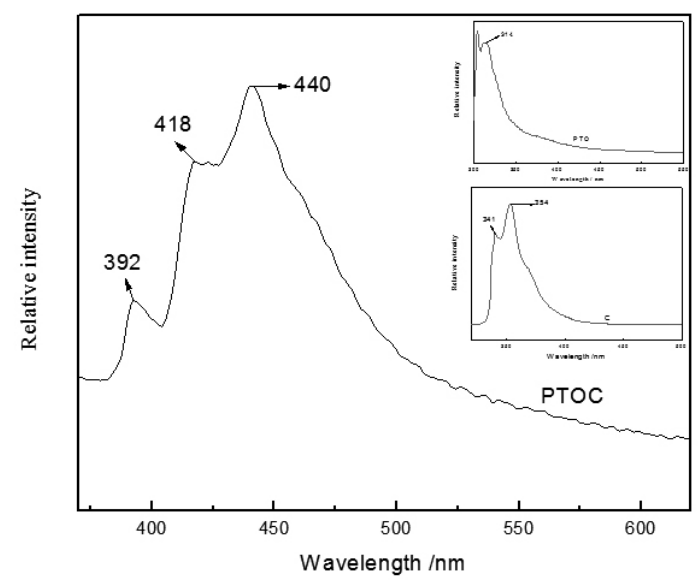

Figure 3: Fluorescence spectra of $\mathrm{C}$, PTO in $\mathrm{CH}_{2} \mathrm{Cl}_{2}$ and the PPTOC [PTO:C(3:1)] films coated on an optically transparent ITO electrode.

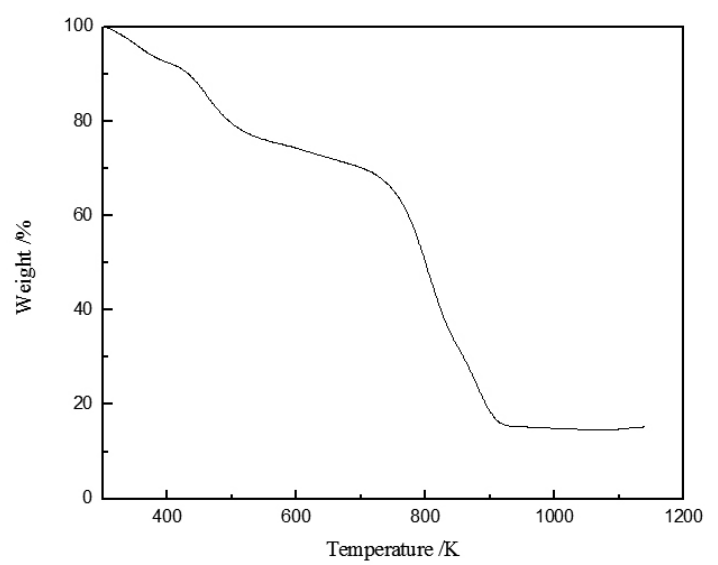

Figure 4: TGA curves of PPTOC [PTO:C(3:1)] films obtained potentiostatically at $1 \mathrm{~V}$ vs $\mathrm{Pt}$ from $\mathrm{CH}_{2} \mathrm{Cl}_{2}$ containing $25 \% \mathrm{BFEE}$ (by volume) .

\section{CONCLUSIONS}

The electrochemical copolymerization of PTO and $\mathrm{C}$ successfully realized in $\mathrm{CH}_{2} \mathrm{Cl}_{2}$ containing $25 \% \mathrm{BFEE}$ (by volume) by direct anodic oxidation of PTO and $\mathrm{C}$ monomer mixtures. The copolymers showed many advantages, such as good electrochemical behavior, good mechanical properties, and favorable thermal stability. Fluorescence studies revealed that the copolymer was good yellow light emitter. Under these conditions, copolymer films combined with the advantages of both PTO and C may meet the application in LEDs as lightemitting films.

\section{REFERENCE}

1.- T. A. SKOTHEIM,in "Handbook of Conducting Polymers" (Marcel Dekker, New York, 1986)

2.- T. A. SKOTHEIM, R. L. ELSEMBAUMER and J . R. REYNOLDS in "Handbook of Conducting Polymer, 2nd edn.," (Marcel Dekker, New York, 1998).

3.- P. BERNIER, S. LEFRANT and G. BIDAN,in“"Advances in Synthetic Metals: Twenty Years of Progress in Science and Technology" (Elsevier, New York, 1999).

4.- Bao. Z, Lovinger. A, J. Chem. Mater. 2607, 11 (1999)

5.- Morin. JF, Leclerc. M, Macromolecules. 8413, 35, (2002).
6.- Brabec. CJ, Sariciftci. NS, Hummelen. JC, Ad. Funct. Mater. 15, 11, (2001)

8.- Zotti. G, Schiavon. GJ, Electroanal. Chem. 385, 163, (1984)

9.- Kaneko. M, Takahashi. K, Tsuchida. EJ, Electroanal. Chem. 255, 220, (187)

10.- Rudge. A, Raistrick. I, Gottesfeld. S, Ferraris. JP, Electrochim. Acta 273, 39, (1994)

11.- Yassar. A, Moustrou. C, Youssoufi. HK, Samat. A, Guglielmetti. R, Garnier. FJ, Chem. Soc. Chem. Commun. 471, (1995).

12.- A.I. Cooper, J. Mater. Chem. 207, 10, (2000)

13.- D.E. Labaye, C. Jerome, V.M. Geskin, et al., Langmuir 5222, 18, (2002)

14.- L. Groenendaal, G. Zotti, P.H. Aubert, S.M. Waybright, J.R. Reynolds, Adv. Mater 855, 15, (2003)

15.- H. Mori, K. Takano, T. Endo, Macromolecules 7342, 42, (2009)

16.- B. Wang, S. Watt, M. Hong, B. Domercq, R. Sun, B. Kippelen, D.M. Collard, Macromolecules 5156, 41, (2008)

17.- Kun. Lu, Yunlong. Guo, Yunqi. Liu, Chongan. Di, Tao. Li, Zhongming. Wei, Gui. Yu, Chunyan. Du, Shanghui. Ye, Macromolecules. 3222, 42, (2009)

18.- Yiyong. Mai, Yongfeng. Zhou, Deyue. Yan, Hongwu. Lu, Macromolecules 9667, 36, (2003)

19.- M. Sak-Bisnar, M. Budimir, S. Kovac, D. Kukulj, L. Duic, J. Polym. Sci.A: PolymChem. 1609, 30, (1992)

20.- B.Y. Lu, C.C. Liu, Y.Z. Li, J.K. Xu, G.D. Liu, Synth. Met. 188,161, (2011). 